\title{
Long-term obesity is associated with depression and neuroinflammation
}

Fernanda B. Lorena ${ }^{1,2}$

https://orcid.org/0000-0002-9545-9767

Bruna P. P do Nascimento ${ }^{1,2}$

https://orcid.org/0000-0003-0036-2936

Esther L. R. A. Camargo 1,3

https://orcid.org/0000-0003-3500-3757

Maria M. Bernardi ${ }^{4}$

https://orcid.org/0000-0002-6860-9416

André R. Fukushima ${ }^{3}$

https://orcid.org/0000-0001-6026-3054

Julia do N. Panizza'

https://orcid.org/0000-0001-8919-8866

Paula de B. Nogueira ${ }^{1}$

https://orcid.org/0000-0002-3233-6663

Marllos E. S. Brandão', 2,3

https://orcid.org/0000-0002-5396-7093

Miriam O. Ribeiro ${ }^{1,2}$

https://orcid.org/0000-0001-8637-676X

\author{
${ }^{1}$ Programa de Distúrbios do \\ Desenvolvimento, Centro de \\ Ciências Biológicas e da Saúde, \\ Universidade Presbiteriana \\ Mackenzie, São Paulo, SP, Brasil \\ ${ }^{2}$ Medicina Translacional, \\ Universidade Federal de São \\ Paulo, São Paulo, SP, Brasil. \\ ${ }^{3}$ Departamento de Pesquisa e \\ Extensão, Faculdade de Ciências da \\ Saúde IGESP, São Paulo, SP, Brasil \\ ${ }^{4}$ Instituto de Ciências da \\ Saúde, Universidade Paulista, \\ São Paulo, SP, Brasil
}

\begin{abstract}
Objective: Obesity is characterized by a state of chronic, low-intensity systemic inflammation frequently associated with insulin resistance and dyslipidemia. Materials and methods: Given that chronic inflammation has been implicated in the pathogenesis of mood disorders, we investigated if chronic obesity that was initiated early in life - lasting through adulthood - could be more harmful to memory impairment and mood fluctuations such as depression. Results: Here we show that prepubertal male rats (30 days old) treated with a high-fat diet $(40 \%)$ for 8 -months gained $\sim 50 \%$ more weight when compared to controls, exhibited depression and anxiety-like behaviors but no memory impairment. The prefrontal cortex of the obese rats exhibited an increase in the expression of genes related to inflammatory response, such as NFKb, MMP9, CCI2, PPARb, and PPARg. There were no alterations in genes known to be related to depression. Conclusion: Long-lasting obesity with onset in prepuberal age led to depression and neuroinflammation but not to memory impairment. Arch Endocrinol Metab. 2021;65(5):537-48
\end{abstract}

Keywords

Juvenile obesity; behavior; depression; neuroinflammation; cognition
Correspondence to:

Miriam O. Ribeiro

Programa de Distúrbios do

Desenvolvimento, Centro de Ciências

Biológicas e da Saúde, Universidade

Presbiteriana Mackenzie

Rua da Consolação, 930, Bld. \#28

01302-907 - São Paulo, SP, Brasil

miriamribeiro@mackenzie.br

Received on Nov/20/2020 Accepted on Jun/18/2021

DOI: $10.20945 / 2359-3997000000400$

\section{INTRODUCTION}

$I^{\prime}$ $t$ is estimated that more than a third of the world's population is overweight or obese (1). White adipose tissue has long been regarded as an energy storage organ only, but this concept has been modified with the discovery of its ability to also secrete numerous proteins, collectively known as adipokines (2). Although white adipocytes synthesize adiponectin, a protein that increases insulin sensitivity (3), most adipokines are proinflammatory, such as leptin (4), resistin (5), IL-6, and $T N F-\alpha(6)$. The hypertrophic adipose tissue exhibits a dysregulation in the production and secretion of proand anti-inflammatory adipokines that leads to a state of chronic, low-grade systemic inflammation related to the pathogenesis of obesity and insulin resistance, hypertension, dyslipidemia, and mood disorders $(7,8)$. Although several other cell types such as macrophages and fibroblasts are found in adipose tissue in addition to adipocytes in individuals who are not overweight, in obesity there is an abundant infiltration in the adipose tissue of macrophages that secrete $T N F-\alpha$ and $I L-6$, increasing the systemic inflammation. Thus, the excess of adipose tissue results in a metabolic imbalance that contributes to complications related to obesity.

The cytokines released by both adipose tissue and immune cells can cross the blood-brain barrier (9) and enter the central nervous system (CNS) where they activate the microglia in the CNS, changing their 
function and morphology, and inducing the secretion of TNF- $\alpha$ and $I L-6(10)$. Studies show an association between neuroinflammation in the brain and emotional and cognitive abnormalities (11). Increased levels of inflammatory markers are present in depressed patients $(12,13)$. Confirming these findings, it has been shown that the induction of inflammation by peripheral administration of lipopolysaccharides leads to IL1 $\beta$ and $T N F \alpha$ release in the brain, inducing depressive behaviors in rodents $(14,15)$.

Adult obesity has been associated with depression $(16,17)$ with a prevalence in obese individuals twice as high as in those of normal weight (16). Mechanisms linking the two disorders include inflammation, oxidative stress, and other endocrine dysfunctions (13). The fact that obese individuals experienced an improvement in their depressive symptoms after diet and weight loss is in line with previous research $(18,19)$. Interconnected limbic brain regions including the ventral tegmental area (VTA), nucleus accumbens (NAc), dorsal striatum, amygdala, hippocampus, and the prefrontal cortex (PFC) are implicated in mediating depression and anxiety (20) and could play a part in these behavior observed in obesity. Corroborating these findings, several studies have shown that inflammatory markers were significantly elevated in the cortex $(21,22)$, striatum (23), NAc (24), and hippocampus $(25,26)$ of obese mice fed a HFD. Another relevant finding is that depressive and anxiety disorders commonly occur together in patients $(27,28)$.

Neuroinflammation is also associated with cognitive impairment. Obese middle-aged adults are at higher risk of cognitive decline (29), particularly on executive function and memory (30). A systematic review revealed a negative association between obesity and cognitive performance at 19-65 years of age (31). However, cross-sectional studies failed to show a higher risk of cognitive decline in late life (29). If in midlife, obesity is associated with an increased risk of cognitive decline, late in life it appears to be neuroprotective (32).

Among prepuberal and puberal children chronic obesity is associated with a high incidence of metabolic alterations (33) and several studies showed deleterious effects on cognition of juvenile obesity (34-37).

Thus, the goals of the present study were to evaluate if chronic obesity initiated in pre-pubertal individuals and lasting until adulthood (38) would lead to cognition impairment and depression in an animal model with obesity induced by a high-fat diet. These are domains known to be affected by multiple systems including thyroid hormones. Indeed, inflammation/ cytokines have been shown to regulated $\mathrm{T} 3$ production and signaling in the brain. (39-42). Thus, we also looked in the present investigation at genes known to be regulated by $\mathrm{T} 3$.

\section{MATERIALS AND METHODS}

All experiments described in the manuscript were conducted in accordance with standards of humane animal care, as outlined in the Ethical Guidelines, and were approved by the Ethics Committee of Mackenzie Presbyterian University (CEUA/UPM $\left.n^{0} 112 / 08 / 2014\right)$.

Animals: 4 week-old male Wistar rats were housed in standard plastic cages $(40 \times 50 \times 20 \mathrm{~cm})$ kept at room temperature $\left(22{ }^{\circ} \mathrm{C}\right)$, with a 12 -hour dark/light cycle starting at 7:00 am and with access to water and food ad libitum. The animals were divided in two groups: Control $(\mathrm{n}=10)$ and Obese $(\mathrm{n}=10)$. Two sets of groups were independently studied.

Obesity-induced by high-fat diet: Animals were treated with a high-fat diet (casein, corn starch, lard, cellulose, DL-Methionine, dextrinized starch, choline bitartrate, dibasic calcium phosphate, mineral premix AIN-93G, vitamin premix AIN-93, cheese, and sucrose, resulting in $40.42 \%$ fat, $19.9 \%$ protein, and $25.67 \%$ carbohydrates, totaling $5,7 \mathrm{kcal} / \mathrm{g}$; Rhoster, Sao Paulo, SP, Brazil) for eight months. They were then tested for glucose tolerance and their plasma cholesterol levels were measured (43). The animals continued HFD throughout the behavioral tests, totaling eight months of treatment. Animals from control group were fed with standard diet (whole corn, soy bran, wheat bran, calcium carbonate, dicalcium phosphate, sodium chloride (common salt), vitamin $\mathrm{A}$, vitamin $\mathrm{D} 3$, vitamin $\mathrm{E}$, vitamin $\mathrm{K} 3$, vitamin $\mathrm{B}$, vitamin $\mathrm{B} 2$, vitamin $\mathrm{B} 6$, vitamin $\mathrm{B} 12$, niacin, calcium pantothenate, folic acid, biotin, choline chloride, iron sulfate, maganese monoxide, zinc oxide, copper sulfate, calcium iodate, sodium selenite, cobalt sulfate, lysine, methionine, BHT, resulting in $4 \%$ fat, $22 \%$ protein, and $54 \%$ carbohydrates, totaling $1.8 \mathrm{kcal} / \mathrm{g}$; Nuvilab CRl; Nuvital, Brazil). Four weeks after the end of the behavior tests the animals were anesthetized and euthanized by anesthetic excess (Urethane - 3,200 $\mathrm{mg} / \mathrm{kg}$ ) followed by decapitation. 
Glucose tolerance test (GTT): Following the establishment of the obesity model, basal glucose was measured after a fasting period of 12 hours using a glucometer (One Touch Ultra, Johnson \& Johnson, São Paulo, SP). The animals were then given glucose intraperitoneally $(2 \mathrm{~g} / \mathrm{kg} \mathrm{BW})$ and glycemia was measured at $30,60,90$, and 120 minutes after the glucose dose, as described by Asensio and cols. (2005) (44).

Plasma triglycerides measurement: Plasma triglycerides were determined after 12 hours fasting period by colorimetry using commercial kits (Triglycerides liquiform, Labtest, Lagoa Santa, MG), following the manufacturer's instructions and a NanoDrop spectrophotometer.

Behavioral testing: All tests were performed between 9 am and 3 pm under dimmed light (15 lux) and were recorded for later analysis by two independent blind observers. The Open Field test was the first one to be performed followed by the Object Recognition test to take advantage of the habituation to the apparatus. Social Recognition, Elevated Plus Maze, Forced Swim, Novelty-suppressed feeding, and Barnes maze tests were performed in this order with a week interval between each one. This was designed to decrease the carryover effect of the tests (Figure 1).

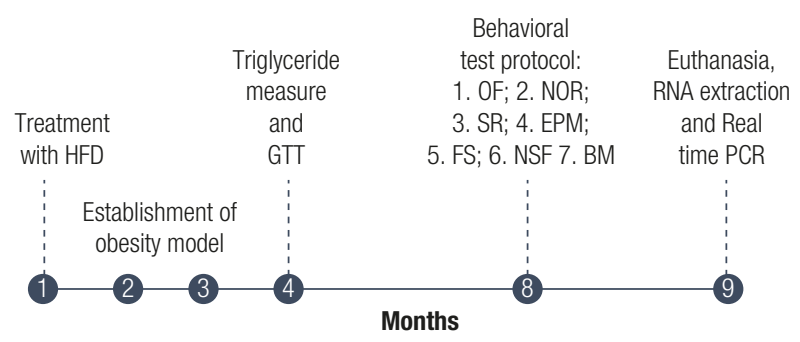

Figure 1. Experimental design.

Open Field test (OF): The open field test was used to evaluate exploratory activity (45). The animals were placed in the center of a circular acrylic arena (diameter $=100 \mathrm{~cm}$ ) divided into four central squares and eight peripheral squares (Insight Ltda, Brazil), in a low-light environment (40 Lux) for 10 minutes. Locomotion (total number of lines crossed with all four paws) in the central and peripheral squares was measured. The test was performed for three consecutive times with a 24 hour interval (46).

Forced Swim Test (FST): This test was performed to evaluate depressive behavior. The animals were placed in a cylindrical plastic vessel, about $80 \mathrm{~cm}$ in height and $40 \mathrm{~cm}$ in diameter with water at $32{ }^{\circ} \mathrm{C}$. The test was performed in two stages, training and testing. In the training stage, the animal was placed for about 5 minutes inside the vessel with water for habituation. 24 hours later the animal was placed for the same period inside the vessel with water. The test was recorded for later analysis of (i) swimming and (ii) immobility time (47).

Elevated Plus Maze test (EPM): This test was performed to evaluate anxiety and used a maze formed by four, $50 \mathrm{~cm}$ long arms (two closed arms and two open arms) suspended $60 \mathrm{~cm}$ from the ground (Insight Ltda, Brazil). The animals were placed in the center and remained in the maze for 5 minutes. The test was recorded for later analysis of the time spent in each type of $\operatorname{arm}(48)$.

Novelty-Suppressed Feeding test (NSF): This test was performed to evaluate anxiety. The animals were fasted for 24 hours prior to the test with free access to water. On the day of the test, they were placed in a square apparatus $(43.2 \mathrm{~cm} \times 43.2 \mathrm{~cm} \times 30 \mathrm{~cm}$ ) with walls and a dark floor. A $20 \mathrm{~cm}$ x $20 \mathrm{~cm}$ white paper square with 100 grams of food on it was placed in the center of the apparatus, under a strong light (860 lumens). This test evaluated the latency for the animal to start to eat the food, with a time limit of 15 minutes. Immediately after the animal ate the food or when the time limit was reached, the animal was placed in its home cage and the latency to eat the food in the cage was evaluated $(49,50)$.

Object Recognition test (OR): This test was performed to evaluate short- and long-term memory and was performed in three stages: training, test, and retest. In the training stage, the animals were placed in the open field arena for 10 minutes with two unknown objects, object A and object B. Three hours later, the test was performed with the animals being placed in the arena for 3 minutes and exposed to object A (known) and object $\mathrm{C}$ (an unknown object). The retest was performed 24 hours after the test and the animals were placed in the arena for 3 minutes and exposed to the known object A and object D (a new unknown object). At each stage, the time spent with each object was recorded (51).

Social recognition test (SR): This test was performed to assess the animal's memory and was performed in two stages. In the first stage, the animal was placed in the center of a rectangular apparatus $(122 \times 37 \times 78 \mathrm{~cm})$ divided into three equal compartments with an access 
door into each of the two-lateral compartments. The animal remained in the central compartment with the access doors closed for 10 minutes for habituation in the apparatus. An unknown animal was then placed inside a metal cage $(30 \times 15 \times 19 \mathrm{~cm})$ in the left compartment and a known animal (from the evaluated animal's cage) was placed in the right compartment. The evaluated animal was placed in the central compartment with the access doors open so that it could move freely between the compartments. The test evaluated the time that the animal interacted with the known and unknown animals $(52,53)$.

Barnes maze test (BM): This test was performed to evaluate spatial memory. The Barnes maze consists of a white apparatus, formed by a $120 \mathrm{~cm}$ diameter circular platform raised $90 \mathrm{~cm}$ from the ground with $18,9 \mathrm{~cm}$ diameter holes arranged equidistantly along the perimeter. Only one of the holes gives access to a dark box that contains bedding located under the platform, which is considered the escape box (54). The test was performed in a room with visual cues such as a square or triangle hanging on the white walls in a fixed position to help orientate the animals. Each animal was placed in the center of the maze under a light-proof box and remained there for 30 seconds. The box was then removed, and the animal was observed in the maze for 5 minutes, during which time the animal could find the escape box. Each animal underwent 8 training sessions for four days in the morning and afternoon. On the fifth day, the test was performed and the number of errors until the escape box was found were evaluated.

$m R N A$ analysis: Four weeks after the end of the behavior tests five animals randomly chosen were anesthetized and euthanized by anesthetic excess (Urethane $-3,200 \mathrm{mg} / \mathrm{kg}$ ) followed by decapitation and the whole brain was harvest followed by microdissections and immediately frozen in liquid nitrogen. The PFC of the animals was evaluated for the expression of mRNA of genes related to neuroinflammation, memory, and thyroid hormone regulated genes. The mRNA expression of all genes was evaluated using the real-time PCR technique. Initially, total tissue RNA extraction was performed with TRizol solution (Invitrogen, Carlsbad, CA, USA - $500 \mu \mathrm{L}$ ) and by colorimetric methods using a NanoDrop 2000 spectrophotometer. After extraction, the reverse transcription reaction was performed for complementary DNA synthesis (cDNA), requiring approximately 2-4 $\mu \mathrm{g}$ of the total RNA obtained, processed using the commercial SuperScrit ${ }^{\mathrm{TM}}$ FirstStrand Synthesis System kit for RT-PCR in Robocycler thermal cycler (Stratagene, La Jolla, CA, USA). Realtime PCR was then performed with the commercial kit QuantiTect ${ }^{\mathrm{TM}}$ SYBR $^{\circledR}$ Green PCR(Qiagen, Valencia CA, USA) and the reaction was performed in the StepOne thermocycler (Applied Biosystems, Foster City, CA, USA). Cyclophilin was used as the housekeeping gene for the normalization of the data obtained.

Statistical analysis: The experimental data were submitted to statistical analysis to assess their relevance using GraphPad software. The statistical significance of the difference between the mean values was analyzed by the Student's t-test (Body weight gain, GTT, Triglyceridemia, FS, EPM, and NSF) or by two-way ANOVA (OF, OR, SR and BM), followed by the Bonferroni's post-test, with a significance level of $\mathrm{p}<$ 0.05 .

\section{RESULTS}

High-fat diet induces metabolic syndrome: After treatment with a high-fat diet for 8 months, the animals developed a very clear clinical picture of metabolic syndrome. Regarding body weight (Figure 2A), the two-way ANOVA revealed a significant effect of the HFD treatment $\left(\mathrm{F}_{1,872}=1032 ; \mathrm{p}<0.0001\right)$ and of the time $\left(\mathrm{F}_{108,872}=71.75 ; \mathrm{p}<0.001\right)$ with interaction between factors $\left(\mathrm{F}_{108,872}=3.586 ; \mathrm{p}<0.001\right)$. The HFD let to an increase in body of $\sim 50 \%(\mathrm{t}=4.789 ; \mathrm{p}=0.0003)$ (Figure 2B). in the GTT test (Figure 2C), the two-way ANOVA showed a significant effect of the HFD $\left(\mathrm{F}_{1,40}\right.$ $=23.64 ; \mathrm{p}<0.0001)$ and in time $\left(\mathrm{F}_{4,40}=14.26 ; \mathrm{p}<\right.$ $0.0001)$ but without interaction between factors $\left(\mathrm{F}_{4,40}\right.$ $=1.842 ; \mathrm{p}=0.139)$. The treatment with HFD led to a hypertriglyceridemia $(t=3.901 ; p=0.0045)$ (Figure 2D) when compared to control animals.

Obesity induces depressive-like behavior, but not memory and learning impairment: To assess the behavioral changes induced by obesity, the animals underwent a series of tests to evaluate exploration, memory, depression, and anxiety. Obese animals presented similar exploratory behavior in the $\mathrm{OF}$ apparatus when compared to the control animals. (Figure 3A). Two-way ANOVA showed no significance regarding the $\mathrm{HFD}$ treatment $(\mathrm{Fl}, 8=2.562 ; \mathrm{p}=0.148)$ or time $(\mathrm{Fl} .866,14.93=2.679 ; \mathrm{p}=0.104)$ but with an interaction between factors $(\mathrm{F} 2,16=3.756 ; \mathrm{p}=0.046)$. Bonferroni's posttest failed to reveal this difference. 

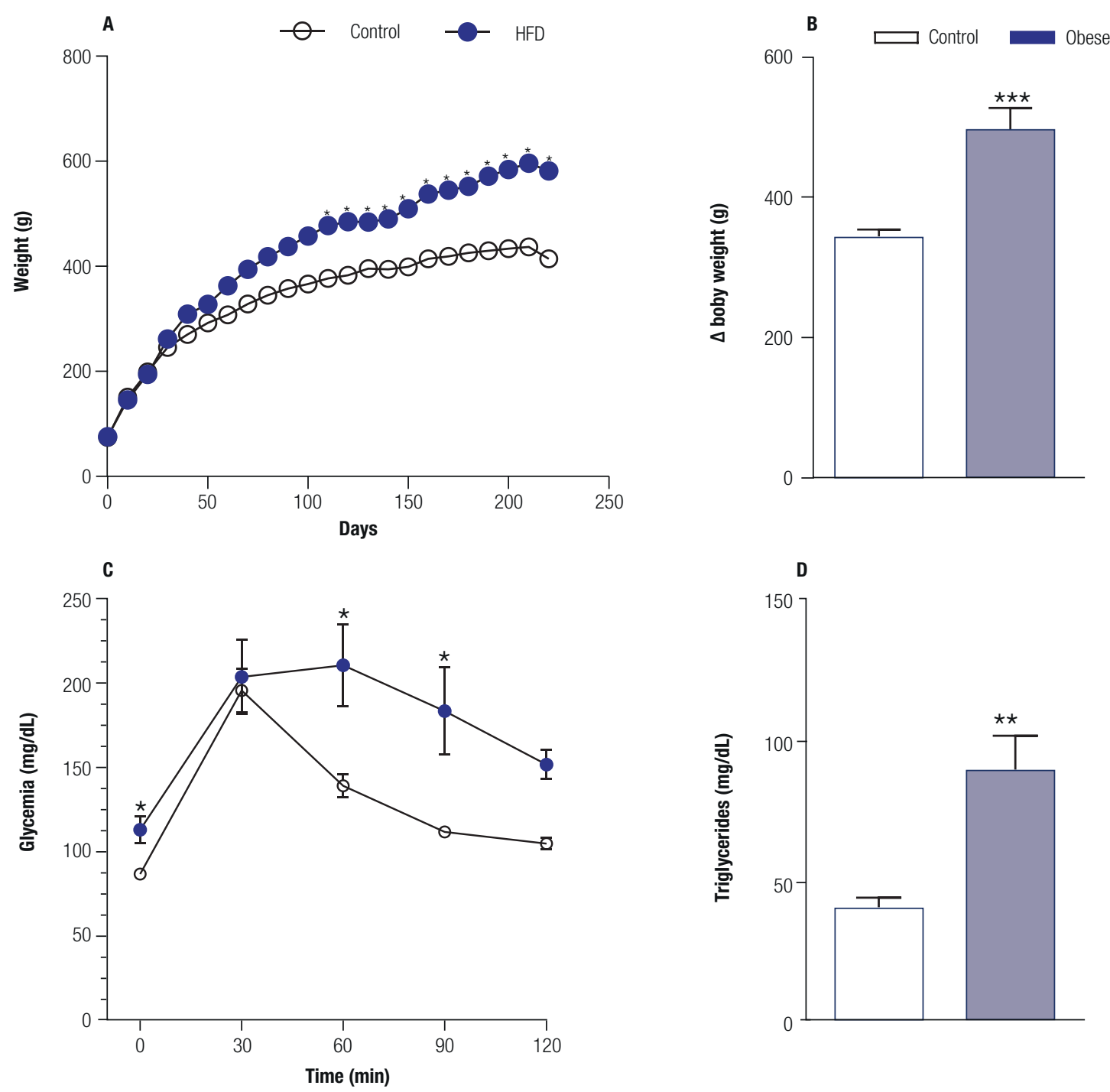

Figure 2. High-fat diet induces metabolic syndrome. A. Body weight chart over the 8 months period of treatment with a high-fat diet (40\%) in the obese group $(n=10)$ and a standard diet in the control group $(n=10)$. B. Delta values for body weight over the 8 months of treatment with a high-fat diet $(40 \%)$ in the obese group and a standard diet in the control group $(p=0.0003)$. C. Glucose tolerance test at the end of the 8 months treatment $(p=0.041)$ with a high-fat diet (40\%) in the obese group and a standard diet in the control group. D. Plasma triglycerides at the end of the 8 months treatment with a high-fat diet $(40 \%)$ in the obese group and standard diet in the control group $(p=0.0045)$. Values are the mean \pm SEM. ${ }^{*} p<0.01$ compared with control animals.

Obese animals presented depressive-like behavior as shown by the forced swim test. The data obtained indicated that obese animals spent about $10 \mathrm{x}$ more time immobile $(\mathrm{t}=3.887 ; \mathrm{p}=0.0025)$ (Figure $3 \mathrm{~B})$ and swam $3 \mathrm{x}$ less $(\mathrm{t}=2.955 ; \mathrm{p}=0.013 \mathrm{l})$ (Figure $3 \mathrm{C})$ than the control animals. Depression is often associated with anxiety, sharing a high rate of comorbidity (55). When subjected to the EPM test, both groups remained in the open $(\mathrm{t}=0.7585 ; \mathrm{p}=0.464)$ and closed $\operatorname{arms}(\mathrm{t}=$ $0.381 ; \mathrm{p}=0.715$ ) for the same time (Figures 3D-E); however, when exposed to a more anxiogenic, the NSF test, the obese animals showed higher latency to eat the food in the apparatus (Figure $3 \mathrm{~F})(\mathrm{t}=2.825 ; \mathrm{p}=0.017$ ) when compared to the control animals, suggesting an increase in anxiety type behavior. The shorter the time taken to start to eat in the home cage exhibited by the obese animals $(t=2.598 ; \mathrm{p}=0.026)$ showed that the delay in eating within the apparatus occurred due to aversive stimulus and not because of an absence of hunger (Figure 3G). 

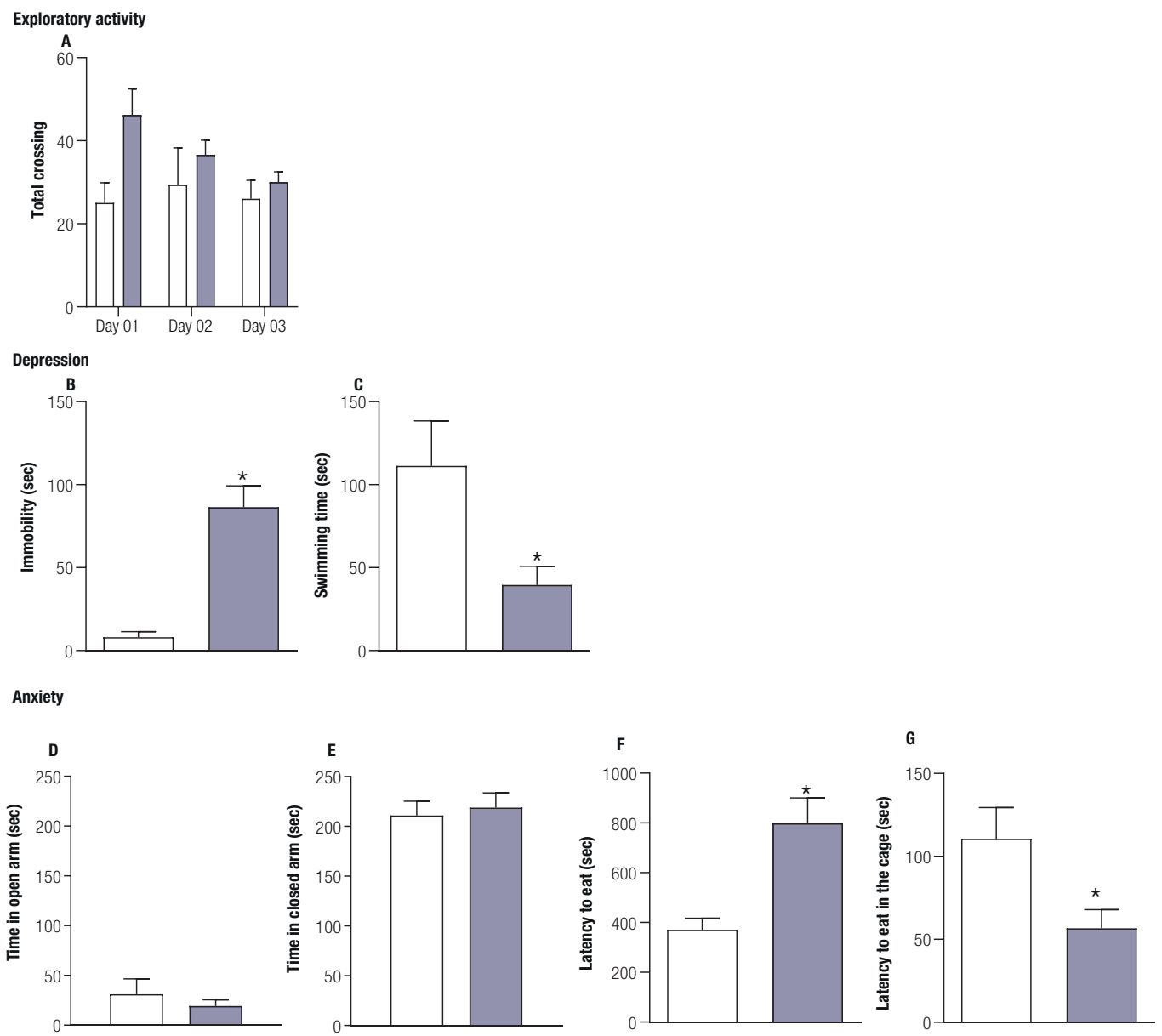

Memory
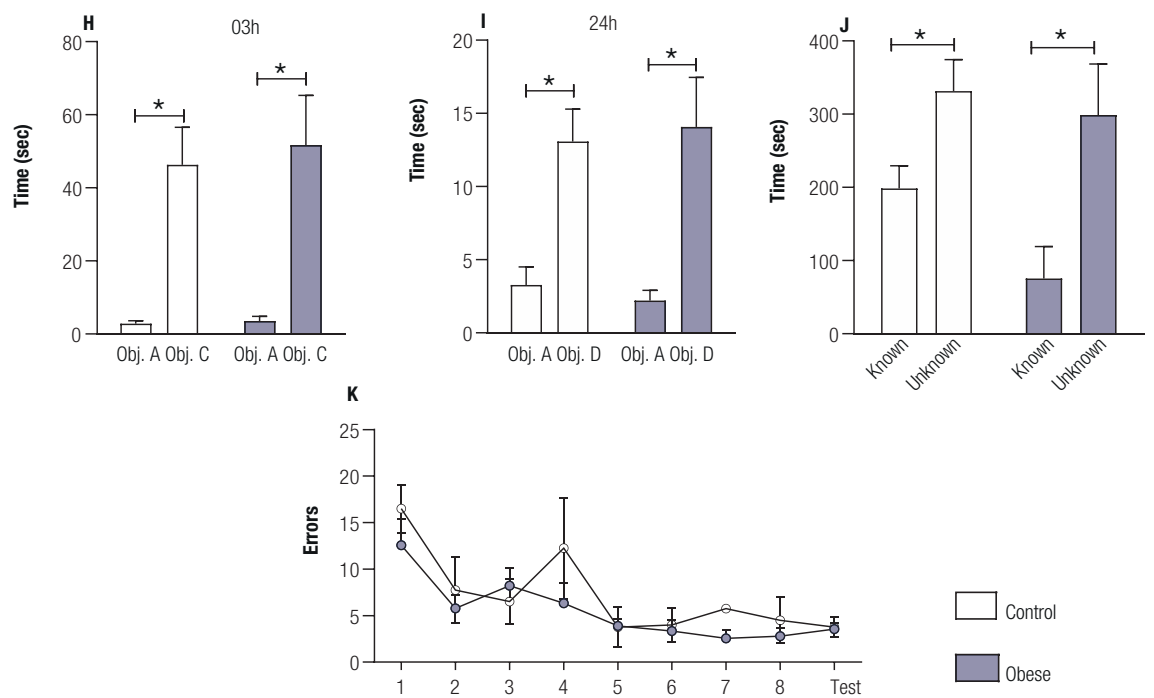

Figure 3. Behavior phenotype in obese animals - Obese $(n=10)$ and Control animals $(n=10)$. A. Frequency of total crossings in the open field test apparatus on the three days of exposure; $\mathbf{B}$. Immobility time in seconds in the forced swim test $(p=0.0025)$; C. Swimming time in seconds of the forced swim test $(p=0.0131)$; $\mathbf{D}$. Time in the open arm in seconds in the elevated plus maze; $\mathbf{E}$. Time in the closed arms in seconds in the elevated plus maze; F. Time in seconds to eat the food in the novelty-suppressed feeding test $(p=0.0172)$; $\mathbf{G}$. Time in seconds to eat in the home cage after noveltysuppressed feeding test $(p=0.0266)$. H. Time in seconds of the animals of each group with each object (Obj. A - known, and Obj. $C$ - unknown) in the object recognition test $3 \mathrm{hrs}$ after the first exposure $(\mathrm{p}<0.0001)$. I. Time in seconds of the animals of each group with each object (Obj. A - known and Obj. D - unknown) in the object recognition test $24 \mathrm{~h}$ after the first exposure $(\mathrm{p}<0.0001)$. J. Time in seconds spent by the animals of each group with the known and unknown animal in the social preference test $(p=0.002)$. K. Number of errors in the attempts to find the exit in Barnes maze test. Values are the mean \pm SEM. 
As depression is associated with an impairment in memory processes (56) the cognitive capacity of the animals was assessed using the NOR, SR, and BM tests. Regarding the NOR, the two-way ANOVA test showed at $3 \mathrm{~h}$ a significant effect of the time $\left(\mathrm{F}_{1,22}=27.04\right.$; $\mathrm{p}<0.0001)$ but not between groups $\left(\mathrm{F}_{1,22}=1206\right.$; $\mathrm{p}=0.7317)$ or for interaction between factors $\left(\mathrm{F}_{1,22}=\right.$ $0.0705 ; \mathrm{p}=0.7931)$. Similar results were observed at 24h with two-way ANOVA test showing a significant effect of the time $\left(\mathrm{F}_{1,22}=24.01 ; \mathrm{p}<0.0001\right)$ but not between groups $\left(\mathrm{F}_{1,22}=0.00025 ; \mathrm{p}=0.9875\right)$ or for interaction between factors $\left(\mathrm{F}_{1,22}=0.2195 ; \mathrm{p}=0.644\right)$. Obese animals recognized the objects to which they were previously exposed, spending significantly more time with the new objects $3 \mathrm{~h}(\mathrm{p}<0.00 \mathrm{l})$ (Figure $3 \mathrm{H}$ ) and $24 \mathrm{~h}$ after exposure to the familiar object ( $\mathrm{p}=$ 0.0014) (Figure 3I). Control animal also recognized new objects $3 \mathrm{~h}(\mathrm{p}=0.0056)$ and $24 \mathrm{~h}(\mathrm{p}=0.012)$.

In the SR, the two-way ANOVA showed a significant effect of the time $\left(\mathrm{F}_{1,16}=13.22 ; \mathrm{p}=0.0022\right)$ but not between groups $\left(\mathrm{F}_{1,16}=2.527 ; \mathrm{p}=0.1315\right)$ or for interaction between factors $\left(\mathrm{F}_{1,16}=0.8469\right.$; $\mathrm{p}=0.3711)$. The obese animals could discriminate the known animal, spending more time with the unknown animal $(\mathrm{p}=0,01 \mathrm{l})$ as control $(\mathrm{p}=0.01 \mathrm{l})$ (Figure $3 \mathrm{~J})$.

The two-way ANOVA analysis of the results of the BM test (Figure $3 \mathrm{~K}$ ) showed a significant effect of time $\left(\mathrm{F}_{8,99}\right)$ $=6.096 ; \mathrm{p}<0.0001)$, but no effect between groups $\left(\mathrm{F}_{1}\right.$, $\left.{ }_{99}=3.057 ; \mathrm{p}=0.0835\right)$ of interaction between factors $\left(\mathrm{F}_{8,99}=0.6042 ; \mathrm{p}=0.7724\right)$. These results showed that the obese animals did not present greater difficulties in finding the exit of the apparatus, exhibiting the same performance as the animals in the control group. Taken together, these data show that obesity did not impair the formation and consolidation of memory.

Diet-induced obesity led to neuroinflammation and a minor decrease in T3 signaling in the PFC: Since obesity is associated with systemic inflammation, we tested if obesity would alter the expression of genes related to inflammation in the PFC, an area known as related to depressive behavior $(57,58)$. A significant increase in the expression of genes involved with inflammation, NFK $(\mathrm{t}=2.899 ; \mathrm{p}=0.03)$ and MMP9 $(\mathrm{t}=3.429 ; \mathrm{p}=0.01)$, and CCl2 $(\mathrm{t}=1.859$; $\mathrm{p}=0.01)$ was observed in the PFC of obese animals when compared to control (Figure 4A). An increase in the expression of mRNA for PPARbeta $(\mathrm{t}=2.768$; $\mathrm{p}=$ $0,04)$ and PPARgama $(\mathrm{t}=2.911 ; \mathrm{p}=0.02)$ was also found in the PFC of obese rats.
Considering that inflammation is associated with the modulation of type D2 deiodinase (Dio2) $(59,60)$, we evaluated if the chronic low-grade inflammation would impact the Dio2 mRNA expression and the thyroid hormone-regulated genes in the PFC of the obese rats (Figure 4B). Among the genes studied, a significant reduction in the expression of Aldblal $(\mathrm{t}=3.200 ; \mathrm{p}=0,01)$ and $R B M 3(\mathrm{t}=5.637 ; \mathrm{p}=0,001)$, positively $\mathrm{T} 3$ - regulated genes, and a significant increase in the expression of HaplnI $(\mathrm{t}=3.683 ; \mathrm{p}=0,01)$, a negative T3- regulated gene were observed. The other genes remained unchanged (Figure 4B). Notably, the mRNA levels for T3 and T4 transporter, OATPICI $(\mathrm{t}=3.390 ; \mathrm{p}=0,01)$, and $\mathrm{TH}$ receptor, $T R \alpha(\mathrm{t}=$ 4.168; $\mathrm{p}=0,005)$ and TR $\beta I(\mathrm{t}=3.045 ; \mathrm{p}=0,02)$ were found to be increased in the frontal cortex of obese rats when compared to controls (Figure 4B). The mRNA levels for Dio2 (Figure 4B) were not affected by obesity when compared to controls. Although the obese animals showed marked depression-like behavior, there was no difference in the expression of genes related to depression or memory such as BDNF and NT-3, which are neurotrophins and mainly associated with increased neurogenesis and cell proliferation $(61,62)$ and $N R 2 B$, CRHR2 e NR3C1, receptors for glucocorticoids and therefore mediate response to stress (63). We only found a significant decrease in mRNA levels of $S G K-1$ in the cortex of obese animals, a gene known to counteract the cortisol-induced reduction in neurogenesis (64) a process associated with depression (Figure 4C).

\section{DISCUSSION}

The present study revealed that chronic obesity with the onset in the prepubertal age induced by a high-fat diet and lasting until adulthood resulted in depressive-like behavior, with no memory impairment. We also showed that obesity was accompanied by a marked increase in the expression of genes involved in the inflammatory response in the PFC. Despite the depressive behavior observed in the obese rats, no changes in the expression of the majority of the genes associated with depression evaluated in our study were observed.

Unexpectedly, obese rats did not exhibit memory impairment. The effect of obesity on cognition is controversial. Several studies show that obesity has a negative impact on memory $(65,66)$, while others showed that memory is not affected by HFD (67) or that HFD can improve memory by increasing the size 



Memory

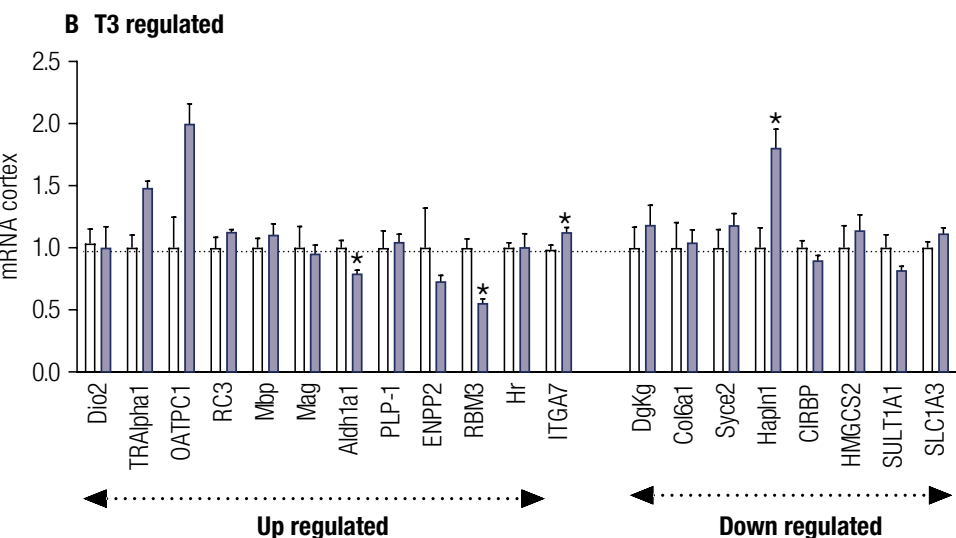

Figure 4. Gene profile in the cortex of obese animals. A. mRNA levels of T3-responsive genes. B. mRNA levels of inflammation genes and C. mRNA levels of genes related to memory and depression, measured by RT-qPCR and using CycloA as the internal control. Values are the mean \pm SEM $(n=5)$ with * $p<0.05$, compared with control rats.

of the hippocampus (68). In a study performed in adult humans with the onset of obesity in the prepuberal age, the author did not find a reduction in the intelligence scores with the persistence of obesity (69).

The onset of depression may be related to several factors and mechanisms and it is associated with neuroinflammation. Increased secretion of proinflammatory cytokines impairs the metabolism and functionality of neurotransmitters, as well as cerebral plasticity (70). These effects may contribute to mood fluctuations (13) such as higher levels of anxiety $(17,71,72)$, depression $(8,73)$, and cognitive and social deficits $(74,75)$. An increase in expression of the inflammatory genes NFK $\beta, M M P 9, C C L 2$ in the cortex, the region most associated with depression (76), was observed in obese rats (Figure 4A). The increase in the expression of mRNA for PPARbeta and PPARgama could be due to the inflammatory status in this region
(77). These data suggest that obesity-induced systemic inflammation increases the inflammatory response in the brain (78), which may be related to the depressivelike behavior found in our obese animals

Inflammatory cytokines may alter the availability, release, and recapture of monoamines in the brain. The idea that there is a relationship between monoamines and the development of depression is due to the observation of decreased monoaminergic function in the brain of depressed individuals $(20,79)$. Activation of the immune system significantly stimulates the activity of serotonin transporters (SERT), decreasing the availability of serotonin (5-HT), a neurotransmitter associated with the onset of depression $(80,81)$.

The results presented in this study showed that the obese rats spent 10 -fold more time immobile in the forced swim test than the control group (Figure 3D-E), which is characteristic of the depressive phenotype (82). 
Immobility is a behavior related to loss of motivation and may be observed in patients with depression (83). In animal models of depression-like behavior, the immobility observed during the forced swim test is decreased with antidepressants, confirming the idea that immobility can be interpreted as a depressive-like behavior in rodents (47). The possibility that obesity could impair locomotor activity due to weight gain was eliminated by the open field test results because the obese animals showed an increase in exploration of the peripheral and central areas of the open field compared to the control animals as shown by the number of line crossings in the open field (Figures 2A-B), suggesting an increase of exploratory behavior. Depression may also be associated with anxiety and although these two diseases are very different, they share a high rate of comorbidity $(55,84,85)$. Accordingly, the results obtained in the novelty-suppressed feeding test, which evaluated anxiety and anhedonia, showed that the obese animals presented anxious behavior, as they took twice as long to start to eat in the apparatus compared to the animals with a standard diet (Figure $3 \mathrm{~F}$ ). The longer latency to explore the environment (Figure 3F) and, therefore, notice and eat the food in the apparatus also characterized anxiety and anhedonia type behavior in these animals (49). Another possible explanation for the delay in eating the food in the apparatus could be due to changes in cue-triggered food seeking behavior mediated by the mesolimbic dopamine system, a pathway that projects from the VTA to the NAc. High fat diet-induced obesity reduces dopamine levels (86) and type 2 dopamine receptors in the striatum $(87,88)$, which could reduce the interest of the rats to eat the food in the apparatus. However, it is unlikely since when the animals were put back in their home cages, the obese animals took less time to eat (Figure 3G). Thus, it is evident that the obese animals were hungry after being deprived of food and that the delay in eating within the test apparatus occurred because of anxiety and/or depression. It is noticeable that the anxious behavior was observed only in the NSF test that is considered a highly anxiogenic test, but not in the EPM (Figure 3D-E).

Another potential mechanism related to depression is hypo and hyperthyroidism. $1 \%$ to $4 \%$ of patients with some type of affective disorder also have thyroid dysfunction (89) and treatment with $\mathrm{TH}$ may help to reverse the symptoms of depression (90). In patients resistant to treatments with antidepressant drugs, such as selective serotonin reuptake inhibitors, the use of T3 in combination with these drugs has been effective, although the patients are euthyroid (91). Studies performed in humans (92-94) and mice (95) suggest that even subtle changes in TH signaling can have a significant effect on neuronal activity and gene expression. Animal studies have shown an increase in serotonin levels in the cerebral cortex of rats after T3 administration and a decrease in serotonin synthesis in the hypothyroid brain (96-99). However, the data obtained in our study does not support the idea that depression induced by HFD could be related to a decrease in $\mathrm{T} 3$ signaling in the brain, since the change in the expression of the genes regulated by T3 was statistically significant but minor. It is also an interesting fact that among the genes often related to depression in the literature, only mRNA levels of the $S G K-I$ gene were decreased in the PFC of obese animals (Figure $4 \mathrm{~B}) . S G K 1$ is a kinase under transcriptional control of various stimuli such as glucocorticoids and has been identified as a mediator of the effects of cortisol on neurogenesis, keeping glucocorticoid receptors active and decreasing hippocampal neurogenesis, which could be of importance for behavioral changes such as depression (64).

Therefore, based on all the results of this study, we can conclude that long-lasting obesity induced by a high-fat diet with the onset in the prepubertal age and lasting until adulthood led to an increase in inflammation in the PFC associated with depression.

Funding: this work was supported by Fundação de Amparo à Pesquisa do Estado de São Paulo (Fapesp n ${ }^{\circ}$ 2014/15556-7; $n^{\circ} 2015 / 13235-1$ ); by the Pró-Reitoria de Extensão (Proex Proc no $1133 / 2019$ ).

Data availability: the data that support the findings of this study are available from the corresponding author upon reasonable request.

Disclosure: no potential conflict of interest relevant to this article was reported.

\section{REFERENCES}

1. Stevens GA, Singh GM, LuY, Danaei G, Lin JK, Finucane MM, et al. National, regional, and global trends in adult overweight and obesity prevalences. Popul Health Metr. 2012;10(1):22.

2. Ouchi N, Parker JL, Lugus JJ,Walsh K. Adipokines ininflammation and metabolic disease. Nat Rev Immunol. 2003;11(2):12.

3. Lihn AS, Pedersen SB, Richelsen B. Adiponectin: action, regulation and association to insulin sensitivity. Obes Rev. 2005;6(1):13-21. 
4. Luo L, Liu M. Adipose tissue in control of metabolism. J Endocrinol. 2016;231(3):R77-99.

5. Park HK, Kwak MK, Kim HJ, Ahima RS. Linking resistin, inflammation, and cardiometabolic diseases. Korean J Intern Med. 2017;32(2):239-47.

6. Aguilar-Valles A, Inoue W, Rummel C, Luheshi GN. Obesity, adipokines and neuroinflammation. Neuropharmacology. 2015;96(Pt A):124-34.

7. Dowlati Y, Herrmann N, Swardfager W, Liu H, Sham L, Reim EK, et al. A meta-analysis of cytokines in major depression. Biol Psychiatry. 2010;67(5):446-57.

8. Castanon N, Lasselin J, Capuron L. Neuropsychiatric comorbidity in obesity: role of inflammatory processes. Front Endocrinol (Lausanne). 2014;5:74.

9. Felger JC, Lotrich FE. Inflammatory cytokines in depression: neurobiological mechanisms and therapeutic implications. Neuroscience. 2013;246:199-229.

10. Kreutzberg GW. Microglia: a sensor for pathological events in the CNS. Trends Neurosci. 1996;19(8):312-8.

11. Guillemot-Legris $O$, Muccioli GG. Obesity-Induced Neuroinflammation: Beyond the Hypothalamus. Trends Neurosci. 2017;40(4):237-53.

12. Levine J, BarakY, Chengappa KN, Rapoport A, Rebey M, Barak V. Cerebrospinal cytokine levels in patients with acute depression. Neuropsychobiology. 1999;40(4):171-6.

13. Hryhorczuk C, Sharma S, Fulton SE. Metabolic disturbances connecting obesity and depression. Front Neurosci. 2013;7:177.

14. Lawson MA, McCusker $\mathrm{RH}$, Kelley $\mathrm{KW}$. Interleukin-1 beta converting enzyme is necessary for development of depressionlike behavior following intracerebroventricular administration of lipopolysaccharide to mice. J Neuroinflammation. 2013;10:54.

15. Reichenberg A, Yirmiya R, Schuld A, KrausT, Haack M, Morag A, et al. Cytokine-associated emotional and cognitive disturbances in humans. Arch Gen Psychiatry. 2001;58(5):445-52.

16. Pereira-Miranda E, Costa PRF, Queiroz VAO, Pereira-Santos M, Santana MLP. Overweight and Obesity Associated with Higher Depression Prevalence in Adults: A Systematic Review and MetaAnalysis. J Am Coll Nutr. 2017;36(3):223-33.

17. Luppino FS, de Wit LM, Bouvy PF, Stijnen T, Cuijpers P, Penninx BW, et al. Overweight, obesity, and depression: a systematic review and meta-analysis of longitudinal studies. Arch Gen Psychiatry. 2010;67(3):220-9.

18. Vaghef-Mehrabany $E$, Ranjbar $F$, Asghari-Jafarabadi $M$, Hosseinpour-Arjmand S, Ebrahimi-Mameghani M. Calorie restriction in combination with prebiotic supplementation in obese women with depression: effects on metabolic and clinical response. Nutr Neurosci. May;24(5):339-53.

19. Galletly C, Moran L, Noakes M, Clifton P,Tomlinson L, Norman R. Psychological benefits of a high-protein, low-carbohydrate diet in obese women with polycystic ovary syndrome - A pilot study. Appetite. 2007;49(3):590-3.

20. Krishnan V, Nestler EJ.The molecular neurobiology of depression. Nature. 2008;455(7215):894-902.

21. Cavaliere G,Trinchese G, Penna E, Cimmino F, Pirozzi C, Lama A, et al. High-Fat Diet Induces Neuroinflammation and Mitochondrial Impairment in Mice Cerebral Cortex and Synaptic Fraction. Front Cell Neurosci. 2019;13:509.

22. Dutheil S, Ota KT, Wohleb ES, Rasmussen K, Duman RS. High-fat diet induced anxiety and anhedonia: impact on brain homeostasis and inflammation. Neuropsychopharmacology. 2016;41(7):1874-87.

23. de Mello AH, Schraiber RB, Goldim MPS, Garcez ML, Gomes ML, de Bem Silveira G, et al. Omega-3 Fatty Acids Attenuate Brain Alterations in High-Fat Diet-Induced Obesity Model. Mol Neurobiol. 2019;56(1):513-24.
24. Décarie-Spain L, Sharma S, Hryhorczuk C, Issa-Garcia V, Barker PA, Arbour N, et al. Nucleus accumbens inflammation mediates anxiodepressive behavior and compulsive sucrose seeking elicited by saturated dietary fat. Mol Metab. 2018;10:1-13.

25. Dinel AL, Andre C, Aubert A, Ferreira G, Laye S, Castanon N. Cognitive and emotional alterations are related to hippocampal inflammation in a mouse model of metabolic syndrome. PLoS One. 2011;6(9):e24325.

26. Klaus F, Paterna JC, Marzorati E, Sigrist H, Gotze L, Schwendener $S$, et al. Differential effects of peripheral and brain tumor necrosis factor on inflammation, sickness, emotional behavior and memory in mice. Brain Behav Immun. 2016;58:310-26.

27. Hirschfeld RM. The Comorbidity of Major Depression and Anxiety Disorders: Recognition and Management in Primary Care. Prim Care Companion J Clin Psychiatry. 2001;3(6):244-54.

28. Sartorius N, Ustün TB, Lecrubier Y, Wittchen HU. Depression comorbid with anxiety: results from the WHO study on psychological disorders in primary health care. Br J Psychiatry Suppl. 1996(30):38-43.

29. Stingl KT, Kullmann S, Ketterer C, Heni M, Häring HU, Fritsche $A$, et al. Neuronal correlates of reduced memory performance in overweight subjects. Neuroimage. 2012;60(1):362-9.

30. Kaur S, Gonzales MM, Tarumi T, Villalpando A, Alkatan M, Pyron $M$, et al. Serum Brain-Derived Neurotrophic Factor Mediates the Relationship between Abdominal Adiposity and Executive Function in Middle Age. J Int Neuropsychol Soc. 2016;22(5):493-500.

31. Smith E, Hay $P$, Campbell $L$, Trollor JN. A review of the association between obesity and cognitive function across the lifespan: implications for novel approaches to prevention and treatment. Obes Rev. 2011;12(9):740-55.

32. Anstey KJ, Cherbuin N, Budge M, Young J. Body mass index in midlife and late-life as a risk factor for dementia: a meta-analysis of prospective studies. Obes Rev. 2011;12(5):e426-37.

33. Burrows R, Gattas V, Leiva L, Barrera G, Burgueño M. [Biological, familial and metabolic characteristics of infantile and juvenile obesity]. Rev Med Chil. 2001;129(10):1155-62.

34. Tsan L, Décarie-Spain L, Noble EE, Kanoski SE. Western Diet Consumption During Development: Setting the Stage for Neurocognitive Dysfunction. Front Neurosci. 2021;15:632312.

35. Del Olmo N, Ruiz-Gayo M. Influence of High-Fat Diets Consumed During the Juvenile Period on Hippocampal Morphology and Function. Front Cell Neurosci. 2018;12:439.

36. Ferreira A, Castro JP, Andrade JP, Dulce Madeira M, Cardoso A. Cafeteria-diet effects on cognitive functions, anxiety, fear response and neurogenesis in the juvenile rat. Neurobiol Learn Mem. 2018;155:197-207.

37. Boitard C, Maroun M, Tantot F, Cavaroc A, Sauvant J, Marchand $A$, et al. Juvenile obesity enhances emotional memory and amygdala plasticity through glucocorticoids. J Neurosci. 2015;35(9):4092-103.

38. Agoston DV. How to Translate Time? The Temporal Aspect of Human and Rodent Biology. Front Neurol. 2017;8:92.

39. Boelen A, van der Spek AH, Bloise F, de Vries EM, Surovtseva $\mathrm{OV}$, van Beeren $\mathrm{M}$, et al. Tissue thyroid hormone metabolism is differentially regulated during illness in mice. J Endocrinol. 2017;233(1):25-36.

40. Mebis L, DebaveyeY, VisserTJ, Van den Berghe G. Changes within the thyroid axis during the course of critical illness. Endocrinol Metab Clin North Am. 2006;35(4):807-21, x.

41. Fekete C, Gereben B, Doleschall M, Harney JW, Dora JM, Bianco AC, et al. Lipopolysaccharide induces type 2 iodothyronine deiodinase in the mediobasal hypothalamus: implications for the nonthyroidal illness syndrome. Endocrinology. 2004;145(4):1649-55. 
42. Lamirand A, Ramaugé $M$, Pierre $M$, Courtin F. Bacterial lipopolysaccharide induces type 2 deiodinase in cultured rat astrocytes. J Endocrinol. 2011;208(2):183-92.

43. Lutz TA, Woods SC. Overview of animal models of obesity. Curr Protoc Pharmacol. 2012 Sep;Chapter 5:Unit5.61.

44. Asensio C, Jimenez M, Kuhne F, Rohner-Jeanrenaud F, Muzzin P. The lack of beta-adrenoceptors results in enhanced insulin sensitivity in mice exhibiting increased adiposity and glucose intolerance. Diabetes. 2005;54(12):3490-5.

45. Seibenhener ML, Wooten MC. Use of the Open Field Maze to measure locomotor and anxiety-like behavior in mice. J Vis Exp. 2015(96):e52434.

46. Hall C, Ballachey EL. A study of the rat's behavior in a field; a contribution to method in comparative psychology. Berkeley: Univ. of California Press; 1932.

47. Porsolt RD, Anton G, Blavet N, Jalfre M. Behavioural despair in rats: a new model sensitive to antidepressant treatments. Eur $\mathrm{J}$ Pharmacol. 1978;47(4):379-91.

48. Walf AA, Frye CA. The use of the elevated plus maze as an assay of anxiety-related behavior in rodents. Nat Protoc. 2007;2(2):322-8.

49. Powell TR, Fernandes C, Schalkwyk LC. Depression-Related Behavioral Tests. Curr Protoc Mouse Biol. 2012;2(2):119-27.

50. Duman RS. Depression: a case of neuronal life and death? Biol Psychiatry. 2004;56(3):140-5.

51. Leger M, Quiedeville A, Bouet V, Haelewyn B, Boulouard M, Schumann-Bard $P$, et al. Object recognition test in mice. Nat Protoc. 2013;8(12):2531-7.

52. Crawley JN. Mouse behavioral assays relevant to the symptoms of autism. Brain Pathol. 2007;17(4):448-59.

53. Novaes GF, Amado D, Scorza FA, Cysneiros RM. Social behavior impairment in offspring exposed to maternal seizures in utero. $J$ Neural Transm (Vienna). 2012;119(6):639-44.

54. Barnes CA. Memory deficits associated with senescence: a neurophysiological and behavioral study in the rat. J Comp Physiol Psychol. 1979;93(1):74-104.

55. Stedenfeld KA, Clinton SM, Kerman IA, Akil H, Watson SJ, Sved AF. Novelty-seeking behavior predicts vulnerability in a rodent model of depression. Physiol Behav. 2011;103(2):210-6.

56. Riedel WJ, Blokland A. Declarative memory. Handb Exp Pharmacol. 2015;228:215-36.

57. Pandey GN, Rizavi HS, Ren X, Fareed J, Hoppensteadt DA, Roberts $\mathrm{RC}$, et al. Proinflammatory cytokines in the prefrontal cortex of teenage suicide victims. J Psychiatr Res. 2012;46(1):57-63.

58. McKlveen JM, Myers B, Flak JN, Bundzikova J, Solomon MB, Seroogy KB, et al. Role of Prefrontal Cortex Glucocorticoid Receptors in Stress and Emotion. Biol Psychiatr. 2013;74(9):672-9.

59. Wittmann G, Harney JW, Singru PS, Nouriel SS, Reed Larsen P, Lechan RM. Inflammation-inducible type 2 deiodinase expression in the leptomeninges, choroid plexus, and at brain blood vessels in male rodents. Endocrinology. 2014;155(5):2009-19.

60. Remaud S, Gothie JD, Morvan-Dubois G, Demeneix BA. Thyroid hormone signaling and adult neurogenesis in mammals. Front Endocrinol (Lausanne). 2014;5:62.

61. Binder DK, Scharfman HE. Brain-derived neurotrophic factor. Growth Factors. 2004;22(3):123-31.

62. Shimazu K, Zhao M, Sakata K, Akbarian S, Bates B, Jaenisch R, et al. NT-3 facilitates hippocampal plasticity and learning and memory by regulating neurogenesis. Learn Mem. 2006;13(3):307-15.

63. Holsboer $\mathrm{F}$, Ising $\mathrm{M}$. Central $\mathrm{CRH}$ system in depression and anxiety - Evidence from clinical studies with $\mathrm{CRH} 1$ receptor antagonists. Eur J Pharmacol. 2008;583(2):350-7.

64. Anacker C, Cattaneo A, Musaelyan K, Zunszain PA, Horowitz M, Molteni R, et al. Role for the kinase SGK1 in stress, depression, and glucocorticoid effects on hippocampal neurogenesis. Proc Natl Acad Sci U S A. 2013;110(21):8708-13.
65. Beilharz JE, Maniam J, Morris MJ. Diet-Induced Cognitive Deficits: The Role of Fat and Sugar, Potential Mechanisms and Nutritional Interventions. Nutrients. 2015;7(8):6719-38.

66. Loprinzi PD, Ponce P, Zou L, Li H. The Counteracting Effects of Exercise on High-Fat Diet-Induced Memory Impairment: A Systematic Review. Brain Sci. 2019;9(6):145.

67. Pancani T, Anderson KL, Brewer LD, Kadish I, DeMoll C, Landfield PW, et al. Effect of high-fat diet on metabolic indices, cognition, and neuronal physiology in aging F344 rats. Neurobiol Aging. 2013;34(8):1977-87.

68. Setkowicz Z, Gaździ,ska A, Osoba JJ, Karwowska K, Majka P, Orzeł $\mathrm{J}$, et al. Does Long-Term High Fat Diet Always Lead to Smaller Hippocampi Volumes, Metabolite Concentrations, and Worse Learning and Memory? A Magnetic Resonance and Behavioral Study in Wistar Rats. PLoS One. 2015;10(10):e0139987.

69. Halkjaer J, Holst C, Sørensen TI. Intelligence test score and educational level in relation to BMI changes and obesity. Obes Res. 2003;11(10):1238-45.

70. Capuron L, Miller AH. Immune system to brain signaling: neuropsychopharmacological implications. Pharmacol Ther. 2011;130(2):226-38.

71. DeJesus RS, Breitkopf CR, Ebbert JO, Rutten LJ, Jacobson RM, Jacobson DJ, et al. Associations between anxiety disorder diagnoses and body mass index differ by age, sex and race: a population based study. Clin Pract Epidemiol Ment Health. 2016;12:67-74.

72. Apryatin SA, Sidorova YS, Shipelin VA, Balakina A, Trusov NV, Mazo VK. Neuromotor Activity, Anxiety and Cognitive Function in the In Vivo Model of Alimentary Hyperlipidemia and Obesity. Bull Exp Biol Med. 2017;163(1):37-41.

73. Bornstein SR, Schuppenies A, Wong ML, Licinio J. Approaching the shared biology of obesity and depression: the stress axis as the locus of gene-environment interactions. Mol Psychiatry. 2006;11(10):892-902.

74. Bocarsly ME, Fasolino M, Kane GA, LaMarca EA, Kirschen GW, Karatsoreos IN, et al. Obesity diminishes synaptic markers, alters microglial morphology, and impairs cognitive function. Proc Natl Acad Sci U S A. 2015;112(51):15731-6.

75. de Wit LM, Fokkema M, van Straten A, Lamers F, Cuijpers $P$, Penninx BW. Depressive and anxiety disorders and the association with obesity, physical, and social activities. Depress Anxiety. 2010;27(11):1057-65.

76. Dusi N, Barlati S, Vita A, Brambilla P. Brain Structural Effects of Antidepressant Treatment in Major Depression. Curr Neuropharmacol. 2015;13(4):458-65.

77. Wahli W, Michalik L. PPARs at the crossroads of lipid signaling and inflammation. Trends Endocrinol Metab. 2012;23(7):351-63.

78. Castanon N, Luheshi G, Laye S. Role of neuroinflammation in the emotional and cognitive alterations displayed by animal models of obesity. Front Neurosci. 2015;9:229.

79. Elhwuegi AS. Central monoamines and their role in major depression. Prog Neuropsychopharmacol Biol Psychiatry. 2004;28(3):435-51.

80. Shelton RC, Miller AH. Inflammation in depression: is adiposity a cause? Dialogues Clin Neurosci. 2011;13(1):41-53.

81. Zhu CB, Lindler KM, Owens AW, Daws LC, Blakely RD, HewlettWA. Interleukin-1 receptor activation by systemic lipopolysaccharide induces behavioral despair linked to MAPK regulation of CNS serotonin transporters. Neuropsychopharmacology. 2010;35(13):2510-20.

82. Can A, Dao DT, Arad M, Terrillion CE, Piantadosi SC, GouldTD. The mouse forced swim test. J Vis Exp. 2012(59):e3638.

83. Willner P. Animal models as simulations of depression. Trends Pharmacol Sci. 1991;12(4):131-6.

84. Ter Meulen WG, Draisma S, van Hemert AM, Schoevers RA, Kupka RW, Beekman ATF, et al. Depressive and anxiety disorders 
in concert-A synthesis of findings on comorbidity in the NESDA study. J Affect Disord. 2021;284:85-97.

85. Thomas J, Jones G, Scarinci I, Brantley P. A descriptive and comparative study of the prevalence of depressive and anxiety disorders in low-income adults with type 2 diabetes and other chronic illnesses. Diabetes Care. 2003;26(8):2311-7.

86. Geiger BM, Haburcak M, Avena NM, Moyer MC, Hoebel BG, Pothos EN. Deficits of mesolimbic dopamine neurotransmission in rat dietary obesity. Neuroscience. 2009;159(4):1193-9.

87. Hajnal A, Margas WM, Covasa M. Altered dopamine D2 receptor function and binding in obese OLETF rat. Brain Res Bull. 2008;75(1):70-6.

88. Hamdi A, Porter J, Prasad C. Decreased striatal D2 dopamine receptors in obese Zucker rats: changes during aging. Brain Res. 1992;589(2):338-40.

89. Hage MP, Azar ST. The Link between Thyroid Function and Depression. JThyroid Res. 2012;2012:590648.

90. Hendrick V, Altshuler L, Whybrow P. Psychoneuroendocrinology of mood disorders. The hypothalamic-pituitary-thyroid axis. Psychiatr Clin North Am. 1998;21(2):277-92.

91. Jackson IM. The thyroid axis and depression. Thyroid. 1998;8(10): 951-6.

92. Cleare AJ, McGregor A, O'Keane V. Neuroendocrine evidence for an association between hypothyroidism, reduced central 5-HT activity and depression. Clin Endocrinol (Oxf). 1995;43(6):713-9.
93. Cleare AJ, McGregor A, Chambers SM, Dawling S, O'Keane V. Thyroxine replacement increases central 5-hydroxytryptamine activity and reduces depressive symptoms in hypothyroidism. Neuroendocrinology. 1996;64(1):65-9.

94. Marcelino CP, McAninch EA, Fernandes GW, Bocco B, Ribeiro MO, Bianco AC. Temporal Pole Responds to Subtle Changes in Local Thyroid Hormone Signaling. J Endocr Soc. 2020;4(11):bvaa136.

95. Bocco BM, Werneck-de-Castro JP, Oliveira KC, Fernandes GW, FonsecaTL, Nascimento BP, et al. Type 2 Deiodinase Disruption in Astrocytes Results in Anxiety-Depressive-Like Behavior in Male Mice. Endocrinology. 2016;157(9):3682-95.

96. Sandrini M, Vitale G, Vergoni AV, Ottani A, Bertolini A. Effect of acute and chronic treatment with triiodothyronine on serotonin levels and serotonergic receptor subtypes in the rat brain. Life Sci. 1996;58(18):1551-9.

97. Mason GA, Bondy SC, Nemeroff $\mathrm{CB}$, Walker $\mathrm{CH}$, Prange AJ, Jr. The effects of thyroid state on beta-adrenergic and serotonergic receptors in rat brain. Psychoneuroendocrinology. 1987;12(4):261-70.

98. Bauer M, Heinz A, Whybrow PC. Thyroid hormones, serotonin and mood: of synergy and significance in the adult brain. Mol Psychiatry. 2002;7(2):140-56.

99. Dayan CM, Panicker V. Hypothyroidism and depression. Eur Thyroid J. 2013;2(3):168-79. 